\title{
Factors associated with physician prescribing behavior of dipeptidyl peptidase-4 inhibitors for type 2 diabetes in the US outpatient population
}

\author{
Xiaojing Ma ${ }^{1}$, Chanhyun Park ${ }^{2}$, Hsien-Chang Lin ${ }^{3}$, Sweta Andrews ${ }^{2}$, Jongwha Chang*2 \\ ${ }^{1}$ Health Outcomes and Pharmacy Practice (HOPP) Division, College of Pharmacy, The University of Texas at Austin, United \\ States \\ ${ }^{2}$ Department of Pharmacy Practice, School of Pharmacy, The University of Texas at El Paso, United States \\ ${ }^{3}$ Applied Health Science, School of Public Health, Indiana University, United States
}

Received: December 4, 2016

Accepted: February 26, 2017

Online Published: March 8, 2017

DOI: $10.5430 /$ jha.v6n2p59

URL: https://doi.org/10.5430/jha.v6n2p59

\begin{abstract}
Objective: Although the use of dipeptidyl peptidase-4 (DPP-4) inhibitors has been increasing after their first approval in 2006, little is known about their prescribing pattern. Therefore, the objective of this study is to evaluate the prescribing pattern of the DPP-4 inhibitors for the treatment of type 2 diabetes mellitus (T2DM) and examine sociological factors associated with physician prescribing behavior in the U.S. outpatient setting.

Methods: This cross-sectional study was conducted utilizing data from the 2006-2010 National Ambulatory Medical Care Survey (NAMCS) and employed the Eisenberg model that explains physician decision making in the context of sociologic influences. For independent variables, the following characteristics were determined based on the Eisenberg model: patient characteristics, physician characteristics, the physician-health care system interaction, and the physician-patient relationship. The dependent variable was the use of DPP-4 inhibitors. Multivariate logistic regressions were used for analyses.

Results: The estimated population size was 535,158,796 patients during five years, and $3.85 \%$ of them were prescribed DPP- 4 inhibitors. Among the patient characteristic-related factors, the odds of the use of DPP-4 inhibitors was $73 \%$ lower in patients with Medicaid compared to patients with private insurance $(\mathrm{OR}=0.27 ; 95 \% \mathrm{CI}, 0.08-0.88 ; p=.030)$. For the physician characteristic-related factor, the odds of prescribing DPP-4 inhibitors for primary care physicians are about $86 \%$ higher than the odds for non-primary care physicians $(\mathrm{OR}=1.86 ; 95 \% \mathrm{CI}, 1.17-2.95 ; p=.008)$. In addition, physicians in private offices were 3.01 times more likely to prescribe DPP-4 inhibitors than physicians in the health maintenance organizations $(\mathrm{HMO})(\mathrm{OR}=3.01$; $95 \%$ CI, 1.03-8.78; $p=.043)$.

Conclusions: Patient characteristics, physician characteristics, and the physician's relationship with the health care system were associated with an increased use of DPP-4 inhibitors. However, the physician's relationship with the patient was not associated with an increased use of DPP-4 inhibitors.
\end{abstract}

Key Words: Dipeptidyl peptidase-4 inhibitor, Prescribing behavior, Eisenberg model, Type 2 diabetes

\footnotetext{
${ }^{*}$ Correspondence: Jongwha Chang; Email: jchang@utep.edu; Address: School of Pharmacy, Department of Pharmacy Practice, The University of Texas at El Paso, United States.
} 


\section{INTRODUCTION}

Diabetes is becoming an important health issue in the U.S. due to high prevalence, substantial economic burden, and an impact on patients' quality of life. In 2012, it affect affected 29.1 million (9.3\%) Americans, including 21 million diagnosed and 8.1 million undiagnosed diabetes patients. ${ }^{[1]}$ For patients with a diagnosis diabetes, the total cost in 2012 was $\$ 245$ billion, including \$176 billion in direct medical costs and $\$ 69$ billion in reduced productivity. ${ }^{[2]}$ More people are being diagnosed with diabetes, and this number is estimated to reach 29 million in 2050. ${ }^{[3]}$

As majority of patients with diabetes are diagnosed with type 2 diabetes mellitus (T2DM), it has raised attention on treatment and management of T2DM. ${ }^{[4]}$ The treatment of T2DM includes lifestyle modification and pharmacological therapy with a goal of achieving normoglycemia. ${ }^{[5]}$ Lifestyle modification, including education, diet, and exercise, is recommended in T2DM treatment and has proved to be effective. ${ }^{[5,6]}$ Patients whose hyperglycemia is not improved with lifestyle modification need pharmacological therapy. ${ }^{[7]} \mathrm{Con}-$ ventional oral antidiabetics approved by the U.S. Food and Drug Administration (FDA) are sulfonylureas, biguanides, glitazones, metaglinide secretagogues and alpha-Glucosidase inhibitors. Until the 1990s, sulfonylureas were the mainstream treatment since it was the first marketed oral antidiabetic. ${ }^{[8]}$ Several studies reported a rapidly increasing trend of biguanides prescriptions in T2DM treatment after it came into the market. ${ }^{[8-12]}$ Currently, biguanide (metformin) is recommended as the initial pharmacological therapy for T2DM patients. ${ }^{[7]}$ With the development of novel antidiabetic agents, the FDA approved DPP-4 inhibitors in 2006 . These agents inhibit the degradation of glucagon-like peptide1 (GLP-1). As an add-on therapy to traditional oral antidiabetics or monotherapy in patients with T2DM, the efficacy and tolerance of DPP-4 inhibitors have been proven. ${ }^{[13-18]}$ Empirical evidences indicated an increasing trend in the use of DPP-4 inhibitors. However, little is known about prescribing trends of antidiabetics for the treatment of T2DM after DDP-4 inhibitors came into the market. ${ }^{[10-12]}$

Physicians, especially specialists, played a vital role in improving T2DM treatment outcomes, but there is a crucial knowledge gap in understanding the sociological influence on physicians prescribing behavior. ${ }^{[19-21]}$ Orzella et al. evaluated the influence of physicians' characteristics on medication prescribing in terms of costs and use. ${ }^{[20]}$ They found that younger physicians were more likely to prescribe medication. Their study also showed that physicians' gender, geography, and working practice were strongly associated with prescribing more expensive medication. A study by Bolen et al. found that the type of provider, graduation year, and gender were not associated with intensification of diabetes medication use. ${ }^{[21]}$ Other factors, such as good physician-patient relationship, might impact physicians prescribing behavior since it was shown to be associated with a positive treatment outcome and a better medication adherence among diabetic patients. ${ }^{[19,22]}$ However, empirical evidence on how these factors affect physicians' prescribing behaviors in the treatment of diabetes is limited.

Physician prescribing behavior is influenced by a number of factors including market intervention, patient's preferences, and sociological influences of patients and physicians. In this paper, we focus on examining physicians' sociological factors associated with their prescribing behavior of DPP-4 inhibitors by employing the Eisenberg model of physician decision making. In 1979, Eisenberg JM proposed the model, which assumes that the physician's behavior of decision making is influenced by the following four factors: (1) patient characteristics, (2) physician's personal characteristics, (3) physician's interaction with his profession, and (4) physician-patient relationship. ${ }^{[23]}$

To our knowledge, no other study examines sociological influences on physician prescribing behavior of DPP-4 inhibitors with a perspective of physicians. The objective of this study is to evaluate the prescribing patterns of the DPP-4 inhibitors for the treatment of T2DM and examine sociological factors associated with physician prescribing behavior in the U.S. outpatient setting.

\section{Methods}

\subsection{Conceptual framework}

Based on the Eisenberg model, we developed our final model using the following four factors to assess the pattern of physician prescribing and diabetes medication selection in patients with T2DM: (1) patient characteristics (age, gender, race/ethnicity and insurance type), (2) physician characteristics (primary care physician or not), (3) the physician-health care system interaction (practice region, metropolitan status, and practice setting), and (4) the physician-patient relationship (the first visit or not). Additionally, we included the type of diabetes medication and survey year in the model.

\subsection{Data source}

Data from the 2006-2010 National Ambulatory Medical Care Survey (NAMCS) were used for these analyses. The NAMCS is a nationally representative survey conducted by the Centers for Disease Control and Prevention (CDC)'s National Center for Health Statistics (NCHS), within NCHS' Division of Health Care Statistics. ${ }^{[2]}$ The sampling unit of the data was the physician-patient encounter or visit, and the data was collected based on a three-stage probability de- 
sign by primary sampling units (PSUs), physician practices within PSUs, and patient visits within practices. ${ }^{[25]}$ Patient Record forms were used to collect the data from the sampled visits. The physician, the physician's staff, or Census field representatives collected the data. ${ }^{[26]}$ For unbiased national estimates, the data was inflated by reciprocals of the proba- bilities of selection at each stage of sampling, adjusted for nonresponse, applied ratio adjustment to fixed totals, and conducted weight smoothing. In general, when using the NAMCS data, estimates with a standard error of 30 percent or less are considered to be reliable. ${ }^{[27]}$

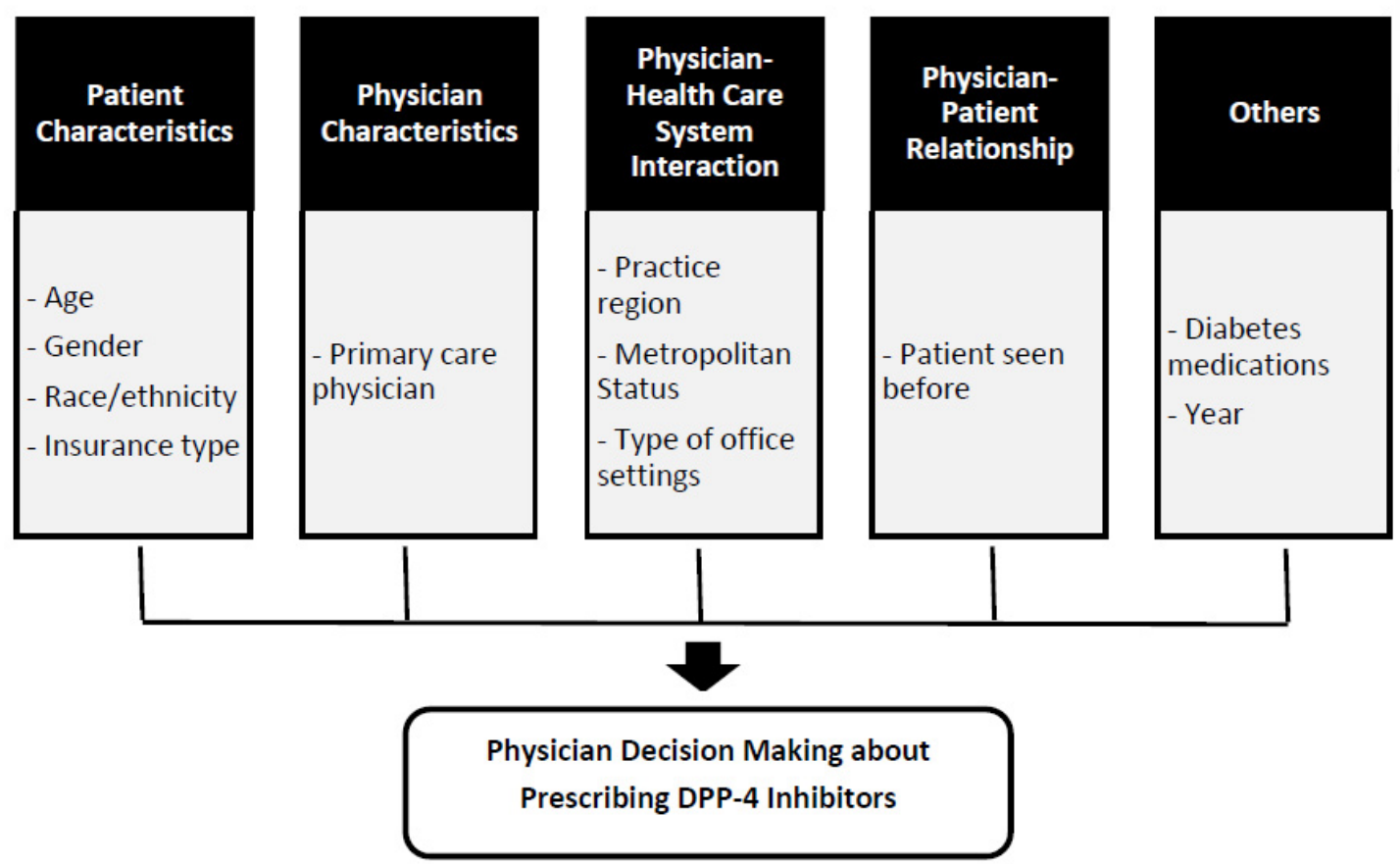

Figure 1. The modified Eisenberg model of physician decision making about prescribing DPP-4 inhibitors

\subsection{Study population}

The target population comprised of adult patients with T2DM in the U.S. Patients were included if they: (1) were aged $\geq 18$ years and (2) had the diagnosis code of T2DM.

\subsection{Measures}

The dependent variable was the use of DPP-4 inhibitors for T2DM. The independent variables were determined based on the Eisenberg model. In the present study, age (18-25, 26-49, 50-65, and $>65$ years), gender (male and female), race/ethnicity (White, Black, Hispanic, and others), and insurance type (Medicare, Medicaid, private, and others) were included as the factors pertaining to patients' characteristics. Secondly, as a factor pertaining to physicians' characteristics, status of primary care physician (yes or no), including internal medicine, family medicine, and pediatrics, were included. Thirds, as the factors pertaining to the physicianhealth care system interaction, practice region (Northeast, Midwest, West, and South), metropolitan status (yes and no), and practice setting (private group, prepaid group, and others) were included in the model. Finally, for the physician-patient Published by Sciedu Press relationship, the status of whether the physician had seen the patient before was included (yes or no). In addition to the above four factors, the types of other diabetes medications (sulfonylureas, biguanide, alpha-glucosidase inhibitor, thiazolidinediones, insulin, and other antidiabetic medications) and survey year (2006, 2007, 2008, 2009, and 2010) were also included in this study.

\subsection{Statistical analyses}

For the precision of estimation, the sample design effects were incorporated into our analyses of the complex survey data. As the sample weight, patient visit weights provided in the data were used to estimate more accurate national estimates. Descriptive statistics and chi-square tests were used to assess the relationship between prescribing DPP-4 inhibitors and independent variables and covariates. Multivariate logistic regression was conducted to estimate the likelihood of prescribing DPP-4 Inhibitors for treating T2DM, while controlling for described covariates. The level for statistical significance was used at 0.05. All Analyses were performed using Stata/SE 13 (Stata Corp., College Station, TX, USA). 


\section{RESUlts}

\subsection{Population characteristics}

Table 1 shows the characteristics of the study population by prescription of DPP-4 inhibitors. The estimated population size was $535,158,796$ patients with T2DM who met the study inclusion criteria during the 5-year study period. Overall, $20,624,566(3.85 \%)$ of patients were prescribed DPP-4 inhibitors. The majority of the study patients were female $(53.8 \%), \geq 50$ years $(82.1 \%)$, white, non-Hispanic $(56.0 \%)$, with Medicare as a primary insurance $(47.1 \%)$. There was a significant difference in the proportion of patients who were prescribed DPP-4 inhibitors, according to age category $(p=.007)$, race/ethnicity $(p<.001)$, and insurance type $(p<.001)$. However, the proportion of patients who were prescribed DPP-4 inhibitors was not significantly different between male and female $(p=.701)$. More than fifty percent of the included physicians were primary care physicians (53.2\%). The proportion of physicians who prescribed DPP4 inhibitors was significantly different between primary care physicians and non-primary care physician $(p=.030)$. Both practice region and metropolitan status were not associated with the proportion of physicians who prescribed DPP-4 inhibitors ( $p=.123$ and $p=.645$, respectively). However, type of practice setting was associated with the proportion of physicians who prescribed DPP-4 inhibitors $(p=.031)$. The physician-patient relationship was also significantly associated with the prescription of DPP-4 inhibitors $(p=.029)$. The proportion of patients who were prescribed DPP-4 inhibitors was significantly different between patients who had their first visit with their physicians and those who had seen their physicians previously $(p=.029)$.

Overall, the most frequently used medication group was biguanide (metformin) (26.1\%), followed by sulfonylureas (17.8\%). Insulin was used in $14.2 \%$, and thiazolidinediones was used in $9.9 \%$ of the patients. Generally, the use of other diabetic medications was related to the use of DPP-4 inhibitors. When sulfonylureas, biguanides (metformin), and thiazolidinediones were prescribed, the proportion of the use of DPP-4 inhibitors was higher (all $p<.001$ ). However, the use of alpha-glucosidase inhibitors was not related to the use of DPP-4 inhibitors $(p=.416)$. Additionally, the survey year was also associated with the prescription of DPP-4 inhibitors $(p<.001)$.

\subsection{Prescribing DPP-4 inhibitors}

The findings pertaining to the use of DPP-4 inhibitors for treating T2DM from the multivariate logistic regression analysis are summarized in Table 2. As the factors related to patient characteristics, the patients' age, gender, race/ethnicity, and insurance type were included in the model to assess the likelihood of prescribing DPP-4 inhibitors. Age was not significantly associated with the use of DPP-4 inhibitors. Although males were less likely to be prescribed DPP-4 inhibitors $(\mathrm{OR}=0.86$; 95\% CI, 0.69-1.08; $p=.185)$ than females, this was not statistically significant. Similarly, compared to Hispanic patients, White and Black patients were more likely to be prescribed DPP-4 inhibitors $(\mathrm{OR}=1.61$; $95 \% \mathrm{CI}, 0.96-2.69 ; p=.068$ and $\mathrm{OR}=1.68 ; 95 \% \mathrm{CI}, 0.93$ $3.06 ; p=.088$, respectively), but these were not statistically significant. Regarding insurance status, the odds of the use of DPP-4 inhibitors was 73\% lower in patients with Medicaid, compared to patients with private insurance $(\mathrm{OR}=0.27$; $95 \% \mathrm{CI}, 0.08-0.88 ; p=.030)$. As a physician characteristicsrelated factor, the odds of prescribing DPP-4 inhibitors for primary care physicians was $86 \%$ higher than those for nonprimary care physicians $(\mathrm{OR}=1.86 ; 95 \% \mathrm{CI}, 1.17-2.95$; $p=.008)$. Among the factors pertaining to the physicianhealth care system interaction, practice region and the type of practice settings were significantly associated with the use of DPP-4 inhibitors. Compared to physicians in the Northeastern part of the U.S., physicians in the Western part of the U.S. were 0.41 times less likely to prescribe DPP-4 inhibitors ( $\mathrm{OR}=0.59 ; 95 \% \mathrm{CI}, 0.37-0.96 ; p=.033)$. Additionally, the odds of prescribing DPP-4 inhibitors was also lower for physicians in the Midwestern and Southern parts of the U.S. than those in the Northeastern part of the US, but were not statistically significant $(\mathrm{OR}=0.70 ; 95 \% \mathrm{CI}, 0.45-1.09$; $p=.118$ and $\mathrm{OR}=0.82 ; 95 \% \mathrm{CI}, 0.53-1.25 ; p=.359$, respectively). Regarding the type of practice setting, physicians in private offices were 3.01 times more likely to prescribe DPP-4 inhibitors than physicians in the health maintenance organizations (HMO) $(\mathrm{OR}=3.01$; 95\% CI, 1.03-8.78; $p=.043$ ). Based on the physician-patient relationship factor, the odds of prescribing DPP-4 inhibitors was not significantly different between patients who were visiting their physicians for the first time and patients who had seen their physicians previously $(\mathrm{OR}=1.19 ; 95 \% \mathrm{CI}, 0.80-1.78 ; p=.390)$.

The use of other diabetes medications was associated with the likelihood of the use of DPP-4 inhibitors. Patients who were prescribed sulfonylureas were approximately twice more likely to be prescribed DPP-4 inhibitors (OR $=1.87 ; 95 \%$ CI, 1.42-2.48; $p<.001)$, and patients who were prescribed biguanide (metformin) were approximately three times more likely to be prescribed DPP-4 inhibitors ( $\mathrm{OR}=2.96$; 95\% CI, 2.27-3.87; $p<.001$ ), holding the other predictors constant. In addition, the odds of the use of DPP-4 inhibitors was also increased with patients receiving insulin $(\mathrm{OR}=1.62 ; 95 \%$ CI, 1.13-2.32; $p=.009$ ). However, the odds of the use of DPP-4 inhibitors was not significantly increased in patients receiving alpha-glucosidase inhibitors $(\mathrm{OR}=1.27 ; 95 \% \mathrm{CI}$, 
$0.14-11.56 ; p=.834)$ and thiazolidinediones ( $\mathrm{OR}=1.23$; inhibitors were more likely to be prescribed in 2007-2010 95\% CI, 0.89-1.72; $p=.214$ ). Regarding survey year, DPP-4 compared to 2006.

Table 1. Descriptive statistics for the study population by prescription of DPP-4 inhibitors (weighted N = 535,158,796)

\begin{tabular}{|c|c|c|c|c|}
\hline Variable & & $\begin{array}{l}\text { Prescribed DPP-4 Inhibitors } \\
\text { Weighted N }(\%)\end{array}$ & $\begin{array}{l}\text { Not Prescribed DPP-4 } \\
\text { Inhibitors Weighted N (\%) }\end{array}$ & $p$-value \\
\hline \multicolumn{5}{|l|}{ 1. Patient characteristics } \\
\hline \multirow{4}{*}{ Age category } & - $18-25$ & $63,544(0.0)$ & $5,906,271(1.1)$ & \multirow{4}{*}{.007} \\
\hline & - 26-49 & $3,031,032(0.6)$ & $86,241,601(16.1)$ & \\
\hline & - 50-64 & $8,830,136(1.6)$ & $172,821,531(32.3)$ & \\
\hline & $\cdot \geq 65$ & $8,699,854(1.6)$ & $249,564,827$ (46.6) & \\
\hline \multirow{2}{*}{ Gender } & - Male & $9,319,503(1.74)$ & $237,718,943(44.4)$ & \multirow{2}{*}{.701} \\
\hline & - Female & $11,305,063(2.11)$ & $238,815,287$ (51.7) & \\
\hline \multirow{4}{*}{ Race/ethnicity } & - White, non-Hispanic & $9,979,910(2.6)$ & $206,386,184(53.4)$ & \multirow{4}{*}{$<.001$} \\
\hline & - Black, non-Hispanic & $2,136,608(0.6)$ & 41,643,697 (10.8) & \\
\hline & - Hispanic & $978,269(0.3)$ & $38,478,454(10.0)$ & \\
\hline & - Other & $1,310,699(0.3)$ & $85,703,015(22.2)$ & \\
\hline \multirow{4}{*}{ Insurance type } & - Private & $10,209,929(2.0)$ & $199,343,188(38.3)$ & \multirow{4}{*}{$<.001$} \\
\hline & - Medicare & $8,152,345(1.6)$ & $236,960,254(45.5)$ & \\
\hline & - Medicaid & $1,033,027(0.2)$ & $36,568,995(7.0)$ & \\
\hline & - All others & $677,797(0.1)$ & $27,278,983(5.2)$ & \\
\hline \multicolumn{5}{|l|}{ 2. Physician characteristics } \\
\hline \multirow{2}{*}{ Primary care physician } & - Yes & $12,941,749(2.4)$ & $272,081,892(50.8)$ & \multirow{2}{*}{.030} \\
\hline & - No & $7,682,817(1.4)$ & $242,452,338(45.3)$ & \\
\hline \multicolumn{5}{|c|}{ 3.Physician-healthcare system interaction } \\
\hline \multirow{4}{*}{ Practice region } & - Northeast & $4,517,649(0.8)$ & $89,784,959(16.8)$ & \multirow{4}{*}{.123} \\
\hline & - Midwest & $4,859,599(0.9)$ & $114,039,352(21.3)$ & \\
\hline & - South & $8,477,530(1.6)$ & $208,696,398(39.0)$ & \\
\hline & - West & $2,769,788(0.5)$ & $102,013,521(19.1)$ & \\
\hline \multirow{2}{*}{ Metropolitan Status } & - Yes & $18,304,835(3.4)$ & $448,139,489(83.7)$ & \multirow{2}{*}{.645} \\
\hline & - No & $2,319,731(0.4)$ & $66,394,741(12.4)$ & \\
\hline \multirow{3}{*}{ Type of practice settings } & - Private group & $99,288(0.0)$ & $12,378,287(2.3)$ & \multirow{3}{*}{.031} \\
\hline & - HMO & $19,159,568(3.6)$ & $459,009,889(85.8)$ & \\
\hline & - Others & $1,365,710(0.3)$ & $43,146,054(8.1)$ & \\
\hline \multicolumn{5}{|c|}{ 4. Physician-patient relationship } \\
\hline \multirow{2}{*}{ Patient seen before } & - Yes & $19,147,492(3.6)$ & $460,60,644(86.1)$ & 029 \\
\hline & - No & $1,477,074(0.3)$ & $53,924,586(10.1)$ & .029 \\
\hline 5. Diabetes medications & & & & \\
\hline Sulfonvlurea & - Yes & $6,758,283(1.3)$ & $88,045,285(16.5)$ & $<001$ \\
\hline & - No & $13,866,283(2.6)$ & $426,488,945(79.7)$ & $<.001$ \\
\hline Biounanides (metformin) & - Yes & $11,278,728(2.1)$ & $128,181,910(24.0)$ & $<001$ \\
\hline & - No & $9,345,838(1.8)$ & $386,352,320(72.2)$ & $<.001$ \\
\hline Alnha-glucosidase inhibitor & - Yes & $63,090(0.0)$ & $703,539(0.1)$ & 416 \\
\hline Aipna-giucosidase innioitor & - No & $20,561,476(3.8)$ & $513,830,691(96.0)$ & .410 \\
\hline Thiazolidinediones (TZD) & - Yes & $3,582,662(0.7)$ & $49,160,071(9.2)$ & $<001$ \\
\hline Iniazolidinediones (IZD) & - No & $17,041,904(3.2)$ & $465,374,159(87.0)$ & $<.001$ \\
\hline Insulin & - Yes & $3,871,726(0.7)$ & $72,309,760(13.5)$ & 045 \\
\hline Insulin & - No & $16,752,840(3.1)$ & $442,224,470(82.6)$ & .045 \\
\hline & - Yes & $337,582(0.1)$ & $5,010,261(0.9)$ & 248 \\
\hline Other diabetes medications & - No & $20,286,984(3.8)$ & $509,523,969(95.2)$ & .248 \\
\hline 6. Other & & & & \\
\hline & - 2006 & $930,101(0.2)$ & $83,784,667$ (15.7) & \\
\hline & - 2007 & $2,469,160(0.5)$ & $98,672,757$ (18.4) & \\
\hline Years & - 2008 & $5,570,754(1.0)$ & $100,285,559(18.7)$ & $<.001$ \\
\hline & - 2009 & $6,472,029(1.2)$ & $125,276,002(23.4)$ & \\
\hline & - 2010 & $5,182,613(1.0)$ & $106,515,245$ (19.9) & \\
\hline
\end{tabular}

Note. The percentages may not add to $100 \%$ because of rounding, and the numbers may not add to total $\mathrm{n}$ because of missing values 
Table 2. The likelihood of prescribing DPP-4 Inhibitors for treating type 2 diabetes

\begin{tabular}{|c|c|c|c|c|}
\hline \multicolumn{2}{|l|}{ Variable [Reference Group] } & \multirow{2}{*}{ Weighted Odds Ratio } & \multirow{2}{*}{ 95\% Confidence Interval } & \multirow{2}{*}{$p$-value } \\
\hline 1. Patient characteristics & & & & \\
\hline \multirow{3}{*}{ Age category [18-25] } & - $26-49$ & 2.06 & $(0.46,1.06)$ & .345 \\
\hline & - $50-64$ & 2.74 & $(0.61,12.36)$ & .190 \\
\hline & - $\geq 65$ & 1.97 & $(0.43,8.92)$ & .379 \\
\hline Gender [Female] & - Male & 0.86 & $(0.69,1.08)$ & .185 \\
\hline \multirow{3}{*}{ Race/ethnicity [Hispanic] } & - White, non-Hispanic & 1.61 & $(0.96,2.69)$ & .068 \\
\hline & - Black, non-Hispanic & 1.68 & $(0.93,3.06)$ & .088 \\
\hline & - Other & 1.70 & $(1.04,2.79)$ & .036 \\
\hline \multirow{3}{*}{ Insurance type [Private] } & - Medicare & 0.87 & $(0.64,1.19)$ & .389 \\
\hline & - Medicaid & 0.27 & $(0.08,0.88)$ & .030 \\
\hline & - All others & 0.63 & $(0.34,1.16)$ & .136 \\
\hline \multicolumn{5}{|l|}{ 2. Physician characteristics } \\
\hline Primary care physician [No] & - Yes & 1.86 & $(1.17,2.95)$ & .008 \\
\hline \multicolumn{5}{|c|}{ 3.Physician-healthcare system interaction } \\
\hline \multirow{3}{*}{ Practice region [Northeast] } & - Midwest & 0.70 & $(0.45,1.09)$ & .118 \\
\hline & - South & 0.82 & $(0.53,1.25)$ & .359 \\
\hline & - West & 0.59 & $(0.37,0.96)$ & .033 \\
\hline Metropolitan Status [No] & - Yes & 1.38 & $(0.78,2.44)$ & .268 \\
\hline \multirow{2}{*}{ Type of practice settings [HMO] } & - Private group & 3.01 & $(1.03,8.78)$ & .043 \\
\hline & - Others & 2.44 & $(0.76,7.82)$ & .134 \\
\hline \multicolumn{5}{|l|}{ 4. Physician-patient relationship } \\
\hline Patient seen before $[\mathrm{No}]$ & - Yes & 1.19 & $(0.80,1.78)$ & .390 \\
\hline \multicolumn{5}{|l|}{ 5. Diabetes medications } \\
\hline Sulfonylurea $[\mathrm{No}]$ & - Yes & 1.87 & $(1.42,2.48)$ & $<.001$ \\
\hline Biguanides (metformin) [No] & - Yes & 2.96 & $(2.27,3.87)$ & $<.001$ \\
\hline Alpha-glucosidase inhibitor [No] & - Yes & 1.27 & $(0.14,11.6)$ & .834 \\
\hline Thiazolidinediones (TZD) [No] & - Yes & 1.23 & $(0.89,1.72)$ & .214 \\
\hline Insulin [No] & - Yes & 1.62 & $(1.13,2.32)$ & .009 \\
\hline Other diabetes medications [No] & - Yes & 1.48 & $(0.51,4.30)$ & .472 \\
\hline \multicolumn{5}{|l|}{ 6. Other } \\
\hline \multirow{4}{*}{ Years [2006] } & - 2007 & 2.53 & $(1.28,5.02)$ & .008 \\
\hline & - 2008 & 5.33 & $(3.08,9.22)$ & $<.001$ \\
\hline & - 2009 & 4.96 & $(2.61,9.44)$ & $<.001$ \\
\hline & - 2010 & 4.87 & $(2.68,8,83)$ & $<.001$ \\
\hline Constant & & 0.00 & $(0.00,0.00)$ & $<.001$ \\
\hline
\end{tabular}

\section{Discussion}

In the past ten years, previous studies have shown rapid adoption of DPP-4 inhibitors into practice. ${ }^{[10-12]}$ Between 2006 and 2008, the proportion of DPP-4 prescriptions increased relatively largely compared to other classes of oral antidiabetics in newly diagnosed diabetic patients. ${ }^{[11]}$ Only one year after Sitagliptin was released, it accounted for $10 \%$ prescriptions of office-based physician visits for T2DM. ${ }^{[12]}$ By 2012, the total number of DPP-4 prescriptions was 3,832,000, which was half the number of sulfonylureas prescriptions. ${ }^{[10]}$ These trends indicted that DPP-4 inhibitors may be an alternative to sulfonylureas in the future. Our study found that biguanide (metformin) was still the most frequently prescribed medication for T2DM treatment, followed by sulfonylureas and insulin. DPP-4 inhibitors were used for a small proportion of patients with T2DM in our study. In this study, DPP-4 inhibitors were more likely to be prescribed in 20082010 compared to 2006 and 2007. Similarly, several previ- ous studies found an increasing trend of DPP-4 inhibitors prescribing. ${ }^{[10-12]}$ Additionally, the prescribing of DPP-4 inhibitors increased with concurrent use of other antidiabetic medications. It indicated that DPP-4 inhibitors were more often prescribed as an add-on therapy. Sulfonylureas and Biguanide were the two most frequently prescribed antidiabetic medications with DPP-4 inhibitors.

This study aimed to identify factors associated with the physicians' prescribing behavior of DPP-4 inhibitors by employing a modified Eisenberg model of physician decision making. Data from NCHS presented here showed that patients' insurance type were related to physician prescribing pattern. Compared to patients with private insurance, the likelihood of prescribing DPP-4 inhibitors was significantly lower in patients with Medicaid; and it was also lower, but not significant, in those with Medicare. This may suggest that a higher standard of care was not readily available to these people. Physicians working with Medicaid patients, follow a 
preferred drug list (PDL) when prescribing medications to Medicaid enrollees. DPP-4 inhibitors were not available on PDL in every states during the study period. Therefore, physicians needed an approval of prescribing DPP-4 inhibitors requiring prior authorization if they thought DPP-4 inhibitors was more appropriate for their patients. Cost-containment strategy, such as Medicaid PDL, has been proven to impact physician behavior. A study by Virabhak S. and Shinogle JA. demonstrated that Medicaid PDL motivated physicians to prescribe fewer off-PDL drugs for Medicaid enrollees. ${ }^{[28]}$ A substantial decreased use of off-PDL drugs was noted with a more restrictive prior authorization process.

We found that primary care physicians were almost two times more likely to prescribe DPP-4 inhibitors than nonprimary care physicians. Primary care physicians, including internal medicine, family medicine, and pediatrics, are the main providers of T2DM care. More than half of primary care physicians prescribed oral antidiabetic drugs in uncomplicated T2DM treatment. ${ }^{[29]}$ Thus, it is important to educate primary care physicians rational use of antidiabetic agents. Physician-patient relationship was related to DPP-4 inhibitors prescribing, but this relationship was not significant in this study. Physician-patient relationship was defined differently in this study. We assumed that patients who have seen physicians previously had a better relationship with the physicians. Patients who trust their physicians, may share details about their condition thereby influencing choice of appropriate drug regimen. This study found that good physician-patient relationship encouraged physicians to prescribe DPP-4 inhibitor.

The physician's interaction with the health care system also influenced prescribing of antidiabetic agents. When compared to the physicians who practiced in the Northeastern part of the U.S., the physicians in the Western part of the U.S. were more likely to prescribe DPP-4 inhibitors. The geographic variance may be due to economic conditions. The economy in the Western part of the U.S. is ahead of other regions' economic performance, in terms of population, employment, and real personal income from 1970 to 2012. ${ }^{[30]}$ It is worth mentioning, that the economy of Western part of the U.S. created 966,707 new jobs in health care and social assistance from 2001 to 2012, which may suggest that more healthcare services were available to patients in the Western part of the country. People with better economic conditions may be more likely to use DPP-4 inhibitors since the cost of DPP-4 inhibitors is high compared to traditional antidiabetic agents. DPP-4 was also more widely accepted by physicians in metropolitan areas, however, the study results were not significant. Additionally, physicians in the private group were three times more likely to prescribe a DPP-4 inhibitor compared to physicians belonging to HMO practice setting. Similarly, physicians belonging to other groups (e.g. other hospital and other health care corporation) were over twice as likely to prescribe a DPP-4 inhibitor compared to those in MHOs. This may suggest that HMO formulary or physician reimbursement mechanisms had an influence on physicians' prescribing behaviors; however, further studies regarding how it affects physicians prescribing DPP-4 inhibitors were needed. Significant results in practice regions and practice settings suggested that cost may be a key factor affecting physician prescribing.

This study has several limitations which should be addressed. First, the NAMCS database does not include several factors which may affect physicians' prescribing behaviors. Cost, patient preference, physician habit prescribing, and other factors could all be reasons for more DPP-4 inhibitor use. The severity of patients' diabetes was not available, which results in the inability to control the type of antidiabetic therapy being prescribed. Second, it is probably biased to define physician-patient relationship only based on whether it is a patient's first visit or subsequent visit. Third, recall bias may occur, considering that the database is built off of self-reporting from the physicians and their staff. Lastly, the most severe cases may not even be represented since the emergency department, inpatient, and urgent care visits were not recorded. Despite these limitations, this study broached the importance of sociological influences on physician prescribing behaviors.

\section{Conculsions}

In conclusion, among the four components of the Eisenberg model of physician decision making, patient characteristics, physician characteristics, and the physician's relationship with the health care system were associated with the increased use of DPP-4 inhibitors. However, the physician's relationship with the patient was not associated with an increased use of DPP-4 inhibitors. Diabetes management training should target primary care physicians since most patients with diabetes are managed in primary care settings. Primary care physicians may be substantial prescribers of DPP-4 inhibitors in the future. The government may consider adding DPP-4 inhibitors in HMO formularies as more studies emerge showing it is a cost-effective alternative.

\section{CONFlicts OF InTEREST Disclosure}

The authors declare they have no conflict of interest. 


\section{REFERENCES}

[1] Center for Disease Control and Prevention. National diabetes statistics report: estimates of diabetes and its burden in the United States, 2014. Atlanta, GA: US Department of Health and Human Services; 2014.

[2] American Diabetes Association. Economic Costs of Diabetes in the U.S. in 2012. Diabetes Care. 2013; 36(4): 1033-1046. PMid: 23468086. https : //doi.org/10.2337/dc12-2625

[3] Boyle JP, Honeycutt AA, Narayan KV, et al. Projection of diabetes burden through 2050 impact of changing demography and disease prevalence in the US. Diabetes Care. 2001; 24(11): 1936-1940. PMid: 11679460. https://doi.org/10.2337/diacare.24.11.1936

[4] Zimmet P, Alberti KGMM, Shaw J. Global and societal implications of the diabetes epidemic. Nature. 2001; 414(6865): 782-787. PMid: 11742409. https://doi.org/10.1038/414782a

[5] American Diabetes Association. Foundations of care: education, nutrition, physical activity, smoking cessation, psychosocial care, and immunization. Sec. 4. In Standards of Medical Care in Diabetes -2015. Diabetes Care. 2015; 38(Suppl 1): S20-S30. PMid: 25537702.

[6] Hermanns N, KulzerB, Maier B, et al. The effect of an education programme (MEDIAS 2 ICT) involving intensive insulin treatment for people with type 2 diabetes. Patient education and counseling. 2012; 86(2): 226-232. PMid: 21715124. https ://doi.org/10.1 016/j.pec. 2011.05 .017

[7] Qaseem A, Humphrey LL, Sweet DE, et al. Oral pharmacologic treatment of type 2 diabetes mellitus: a clinical practice guideline from the American College of Physicians. Annals of internal medicine. 2012; 156(3): 218-231. PMid: 22312141. https: //doi.org/10.7326/0003-4819-156-3-201202070-00011

[8] Cohen FJ, Neslusan CA, Conklin JE, et al. Recent antihyperglycemic prescribing trends for US privately insured patients with type 2 diabetes. Diabetes Care. 2003; 26(6): 1847-1851. PMid: 12766121. https://doi.org/10.2337/diacare.26.6.1847

[9] Wysowski DK, Armstrong G, Governale L. Rapid increase in the use of oral antidiabetic drugs in the United States, 1990-2001. Diabetes Care. 2003; 26(6): 1852-1855. PMid: 12766122. https: //doi.org/10.2337/diacare.26.6.1852

[10] Turner LW, Nartey D, Stafford RS, et al. Ambulatory treatment of type 2 diabetes in the US, 1997-2012. Diabetes Care. 2014; 37(4): 985-992. PMid: 24198301. https ://doi.org/10.2337/dc13-2 097

[11] Desai P, Desai C, Panchal A, et al. A drug prescribing pattern study in Diabetes mellitus: An outpatient study. J Pharm Sci. 2014; 5(1): 2271-3681.

[12] Desai NR, Shrank WH, Fischer MA, et al. Patterns of medication initiation in newly diagnosed diabetes mellitus: quality and cost implications. Am J Med. 2012; 125(3): 302.e1-302.e7. PMid: 22340932. https://doi.org/10.1016/j.amjmed.2011.07.033

[13] Alexander GC, Sehgal NL, Moloney RM, et al. National trends in treatment of type 2 diabetes mellitus, 1994-2007. Arch Intern Med 2008; 168(19): 2088-2094. PMid: 18955637. https://doi.org/ 10.1001/archinte.168.19.2088

[14] DeFronzo RA, Hissa MN, Garber AJ, et al. The Saxagliptin 014 Study Group Study Group. The efficacy and safety of saxagliptin when added to metformin therapy in patients with inadequately controlled type 2 diabetes with metformin alone. Diabetes Care. 2009; 32(9): 1649-1655. PMid: 19478198. https://doi.org/10.233 $7 / d c 08-1984$

[15] Taskinen MR, Rosenstock J, Tamminen I, et al. Safety and efficacy of linagliptin as add -on therapy to metformin in patients with type 2 diabetes: a randomized, double -blind, placebo -controlled study. Dia- betes, Obesity and Metabolism. 2011; 13(1): 65-74. PMid: 21114605. https://doi.org/10.1111/j.1463-1326.2010.01326.x

[16] Vilsbøll T, Rosenstock J, Yki -Järvinen H, et al. Efficacy and safety of sitagliptin when added to insulin therapy in patients with type 2 diabetes. Diabetes, Obesity and Metabolism. 2010; 12(2): 167 177. PMid: 20092585. https://doi .org/10.1111/j.1463-132 6.2009.01173.x

[17] DeFronzo RA, Fleck PR, Wilson CA, et al. The Alogliptin Study 010 Group. Efficacy and safety of the dipeptidyl peptidase-4 inhibitor alogliptin in patients with type 2 diabetes and inadequate glycemic control a randomized, double-blind, placebo-controlled study. Diabetes Care. 2008; 31(12): 2315-2317. PMid: 18809631. https://doi .org/10.2337/dc08-1035

[18] Nowicki M, Rychlik I, Haller H, et al. Long-term treatment with the dipeptidyl peptidase-4 inhibitor saxagliptin in patients with type 2 diabetes mellitus and renal impairment: a randomised controlled 52-week efficacy and safety study. IJCP. 2011; 65(12): 1230-1239. https://doi.org/10.1111/j.1742-1241.2011.02812.x

[19] Blonde L, Russell-Jones D. The safety and efficacy of liraglutide with or without oral antidiabetic drug therapy in type 2 diabetes: an overview of the LEAD 1-5 studies. Diabetes, Obesity and Metabolism. 2009; 11(s3): 26-34. PMid: 19878259. https: //doi.org/10.1111/j.1463-1326.2009.01075.x

[20] Nam S, Chesla C, Stotts NA, et al. Barriers to diabetes management: patient and provider factors. Diabetes Res Clin Pract. 2011; 93(1): 1-9. PMid: 21382643. https://doi.org/10.1016/j.diabres. 2011.02 .002

[21] Orzella L, Chini F, Rossi PG, et al. Physician and patient characteristics associated with prescriptions and costs of drugs in the Lazio region of Italy. Health Policy. 2010; 95(2): 236-244. PMid: 20047773 https://doi.org/10.1016/j.healthpol.2009.12.005

[22] Bolen SD, Bricker E, Samuels TA, et al. Factors associated with intensification of oral diabetes medications in primary care providerpatient dyads: a cohort study. Diabetes Care. 2009; 32(1): 25-31. PMid: 18931096. https://doi.org/10.2337/dc08-1297

[23] Lee YY, Lin JL. How much does trust really matter? A study of the longitudinal effects of trust and decision-making preferences on diabetic patient outcomes. Patient Couns Health. 2011; 85(3): 406-412. PMid: 21269794. https : //doi.org/10.1016/j . pec. 2010.12. 005

[24] Eisenberg JM. Sociologic influences on decision-making by clinicians. Ann Intern Med. 1979; 90(6): 957-964. PMid: 443692. https : //doi .org/10.7326/0003-4819-90-6-957

[25] Centers for Disease Control and Prevention. Survey Content for the National Ambulatory Medical Care Survey and National Hospital Ambulatory Medical Care Survey. Atlanta, GA: US Department of Health and Human Services. Updated June 2, 2009. Accessed May 5, 2016. Available from: http://www.cdc.gov/nchs/data/ah cd/body_NAMCSOPD.pdf

[26] Centers for Disease Control and Prevention. Ambulatory Health Care Data: Scope and Sample Design. Atlanta, GA: US Department of Health and Human Services. Updated November 6, 2015. Accessed May 5, 2016. Available from: http://www.cdc.gov/nchs/ahc d/ahcd_scope.htm\#namcs_scope

[27] Centers for Disease Control and Prevention. Ambulatory Health Care Data: Data Collection and Processing. Atlanta, GA: US Department of Health and Human Services. Updated November 6, 2015. Accessed May 5, 2016. Available from: http://www.cdc.gov/nchs /ahcd/ahcd_data_collection.htm\#namcs_collection

[28] Centers for Disease Control and Prevention. Ambulatory Health Care Data: Reliability of Estimates. Atlanta, GA: US Department of Health and Human Services. Updated November 6, 2015. Accessed 
May 5, 2016. Available from: http://www.cdc.gov/nchs/ahc d/ahcd_estimation_reliability.htm

[29] Virabhak S, Shinogle JA. Physicians' prescribing responses to a restricted formulary: the impact of Medicaid preferred drug lists in Illinois and Louisiana. Am J Manag Care. 2005; 11: SP14-20. PMid: 15700905 .
[30] Jingi AM, Nansseu JRN, Noubiap JJN. Primary care physicians' practice regarding diabetes mellitus diagnosis, evaluation and management in the west region of Cameroon. BMC endocrine disorders. 2015; 15(1): 1. PMid: 25881080. https://doi.org/10.1186/s1 2902-015-0016-3 